\title{
TVERRFAGLEG PRAKSIS GJEV AUKA INNSIKT
}

\section{Laering. Samarbeid i praksisstudiene mellom studentar i} ergoterapi og sjukepleie ga innsikt i kvarandre sin kompetanse.
STUDENTPROSJEKT:

Artikkelen bygger på

$50 \%$ pralisis $50 \%$ teori

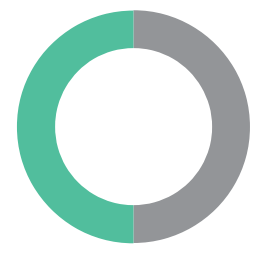

DOI-NUMMER:

10.4220/Sykepleiens.2016.56707

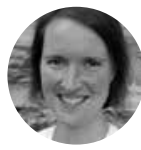

Møyfrid Kalvenes, ergoterapiavdelinga, Haukeland universitetssjukehus

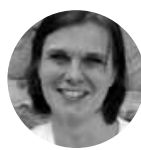

Hege Storlid, spinalein-

inga, Haukeland universitetssjukehus

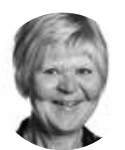

Kari Margrete Hjelle, førstelektor, Høgskolen i Bergen, bachelorutdanning $i$ ergoterapi

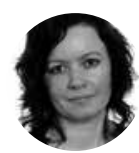

Kristin Tuven, Høgskolelektor, Haraldsplass Diakonale Høgskole, bachelorutdanning i sykepleie

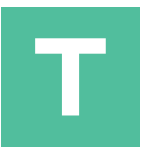

verrprofesjonelt samarbeid er ei viktig føring for rehabilitering, og ulike profesjonsperspektiv er naudsynt for at pasientar skal kunna oppleva mestring (1). Helsetenestene har i større grad vorte spesialiserte, og dermed òg fragmenterte, noko som skapar utfordringar i samarbeid mellom profesjonelle tenesteytarar og mellom tenesteytarar og pasientar (2).

Målet med denne artikkelen er å drøfta studentar si læring av tverrprofesjonelt samarbeid ved å delta i fagutviklingsarbeid i praksisstudie.

AUKT SATSING. Tverrprofesjonelt samarbeid er eit aukande satsingsområde blant helsepersonell og for utdanningsinstitusjonar (2). Studentar som får erfaring i å samarbeida med studentar og profesjonsutøvarar frå ulike helsefagutdanningar er venta å få auka forståing for andre yrkesgrupper sin kompetanse (3). Slik samarbeidslæring bidreg til å styrka profesjonsidentitet og tryggleik på eiga rolle sett i forhold til andre yrkesgrupper. Det er difor tilrådt at studentar frå ulike helsefag har felles læringssituasjonar i praksisstudie og høve til tverrprofesjonelt samarbeid gjennom felles prosjektoppgåver. For å sikra gode og heilskaplege helsetenester i framtida må difor tverrprofesjonalitet, tidleg innsats og brukarmedverknad speilast i utdanninga (3). Nyare forsking på læringsmodellar syner at samarbeidslæring og trygg profesjonsidentitet kan utviklast i ein tverrprofesjonell læringssituasjon (4).

KBP. Kunnskapsbasert praksis (KBP) er ei anna viktig føring for rehabiliteringsarbeidet. KBP inneber at helsearbeidaren baserer faglege val på tidlegare forsking, erfaring og pasientens behov (5). Systematisk innsamling av kunnskap frå ulike kjelder forventast å betra kvaliteten på helsetenesta og er ein del av studentens opplæring (5). KBP brukt i tverrprofesjonelt samarbeid bidreg til fleire synsvinklar på aktuelt problem og kan betra praksis (6). Ei viktig føresetnad for å lukkast er ei felles forståing av KBP blant helseprofesjonar som nyttar metoden (6).

LERINGSARENA. Haukeland universitetssjukehus (HUS) er ein viktig læringsarena for sjukepleiar- og andre helsefagstudentar. Frå 2011 til 2013 vart det gjennomført eit studentprosjekt ved sjukehuset med vekt på tverrprofesjonelt samarbeid og KBP. Prosjektet var eit samarbeid mellom ergoterapiavdelinga og spinaleininga ved HUS, Bachelor i sykepleie ved Haraldsplass Diakonale Høgskole (HDH) og bachelor i ergoterapi ved Høgskolen i Bergen (HiB). Studentar frå begge utdanningsinstitusjonane var i praksisstudie ved Spinaleininga, ei rehabiliteringseining for personar med ryggmargskade. Prosjektet vart finansiert av utviklingsmiddel, spesielt knytt til læring i praksisstudie for høgskulestudentar (7).

SAMARBEID. Studentprosjektet skulle medverka til tettare samarbeid mellom ergoterapeut- og sjukepleiarstudentar i praksisstudiet og tettare samarbeid mellom praksisfelt og utdanningsinstitusjonane. I tillegg skulle det fremja brukarmedverknad i aktivitetar i dagleglivet (ADL), samt styrka det tverrprofesjonelle samarbeidet mellom ergoterapeutar og sjukepleiarar ved Spinaleininga. Prosjektet vektla korleis ein kunne implementera KBP i påkledingstrening for pasientar med ryggmargskade, og var slik ein del av fagutviklingsarbeidet ved eininga. Målet med denne artikkelen er å drøfta studentar si læring av tverrprofesjonelt samarbeid ved å delta i fagutviklingsarbeid i praksisstudiet.

PROSJEKTET. Studentprosjektet hadde leiingsforankring i Ergoterapiavdelinga og Spinaleininga ved HUS. Prosjektet var tredelt og
Fakta

Hoved-

budlskap

Studentar som deltek i tverrprofesjonelt samarbeid (TPS) i praksisstudieterventaåfåauka forståing for andre sin kompetanse, itillegg tilå styrka eigen profesjonsidentitet. Denne artikkelen drøftar studentar si læring av TPS vedådelta i fagutviklingsarbeid praksisstudie etter modell for kunnskapsbasert praksis.

\section{Nøkkelord}

Les mer og finn litteraturhenvisninger på våre nettsider

- Samarbeid

- Sykepleierutdanning

- Praksis

- Ergoterapiutdanning

- Rehabilitering 


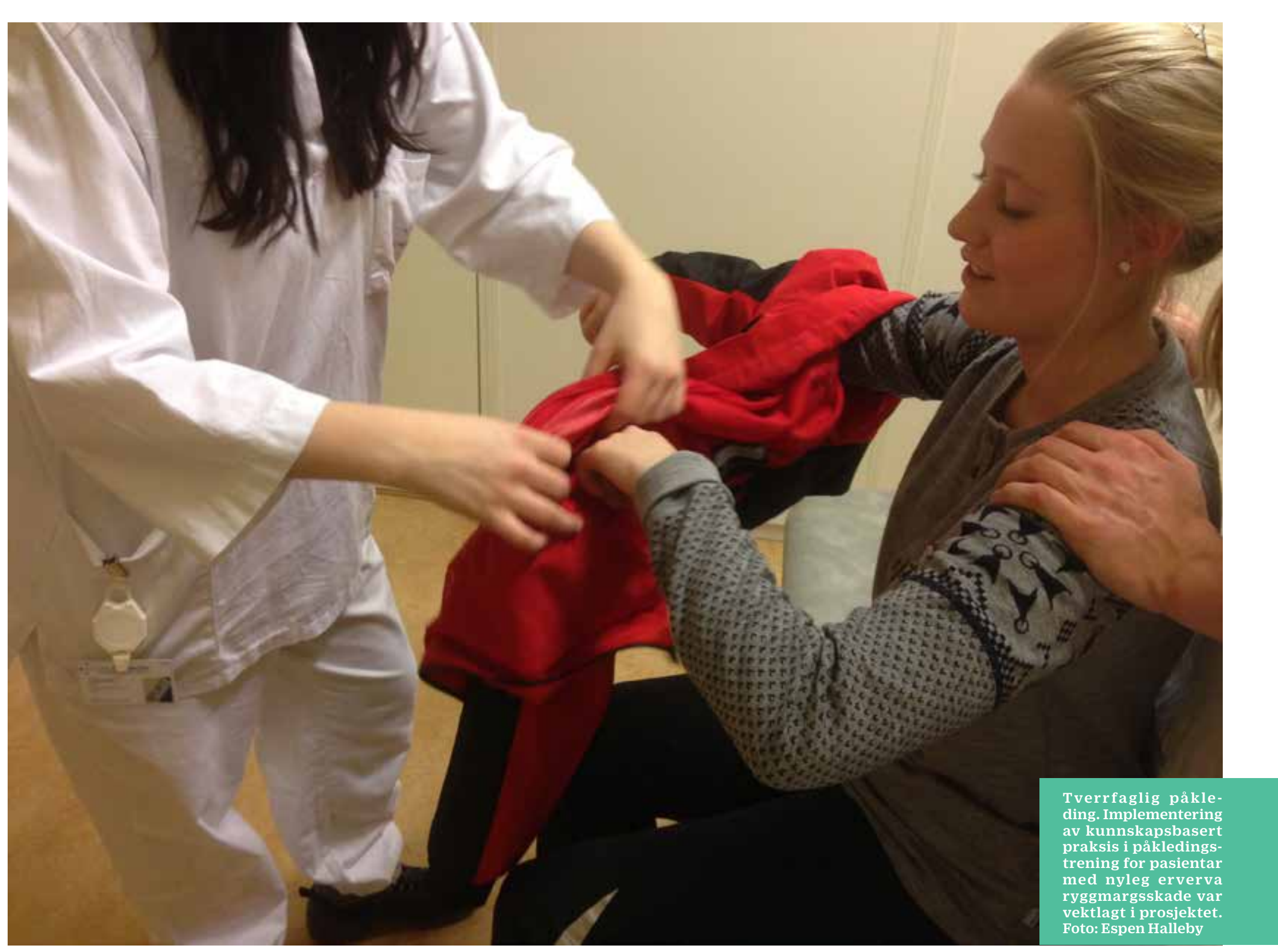

gjennomført i perioden september 2011 til mars 2013.

Overordna prosjektgruppe bestod av prosjektleiar (ergoterapeut) og delprosjektleiar (sjukepleiar), ved spinaleininga, og prosjektmedarbeidarar (høgskulelektorar) frå HiB og HDH. Prosjektgruppa utarbeidde prosjektplan og søkte om prosjektmiddel. Prosjektleiarane hadde ansvar for informasjonsflyt mellom partane og rettleiing av studentane. Høgskulelektorane informerte studentane om prosjektet og deltok i prosjektgruppemøte og på avsluttande møte for kvart delprosjekt der studentane presenterte arbeidet dei hadde gjort.

PRAKSISPERIODE. Prosjektet inngjekk som ein del av studentane sitt ordinære praksisstudie på ein arena der tverrprofesjonelt samarbeid allereie var godt etablert. Nokre studentar hadde eit ynskje om praksisstudie ved spinaleininga, andre fekk tildelt praksisstudieplassen av høgskulen. I prosjektperioden var åtte grupper med andre års sjukepleiarstudentar (n=15), og fire grupper med andre eller tredje års ergoterapeutstudentar $(n=8) i$ praksisstudiet ved eininga.
Praksisperiodane ved dei ulike utdanningane var overlappande og sjukepleiarstudentane hadde noko kortare praksisstudie enn ergoterapeutstudentane (fire eller seks veker, versus elleve veker). Det vart dermed eit byte av sjukepleiarstudentar midtvegs i ergoterapeutstudentane sin praksisperiode. Ergoterapeutstudentane fekk 
ansvar for å vidareformidla prosjektstatus til nye sjukepleiarstudentar. Det var eit ynskje òg å inkludera fysioterapeutstudentar, men dette var ikkje mogleg då praksisperiodane fall på ulik tid.

Pasientar ( $n=6)$ med nyleg erverva ryggmargskade deltok i prosjektet. Pasientane hadde ulikt funksjonsnivå med lammelser i både over- og underekstremitetane, eller berre i underekstremitetane.

GJENNOMFØRING. I praksisstudia arbeidde studentane to dagar i veka à tre timar med prosjektet og deltok elles i dagleg pasientretta arbeid ved spinaleininga. Studentane disponerte eit kontor som dei nytta til prosjektarbeidet. Problemstillinga som studentane skulle arbeida med var: Korleis kan pasien tar med skade $i$ ryggmargen meistra påkleding tidleg i rehabiliteringsprosessen? Studentane avslutta kvart delprosjekt med å utarbeida ein rapport der dei summerte opp resultata frå dei enkelte delprosjekta og erfaringar knytt til samarbeidsprosessar. Rapporten var utgangspunkt for neste delprosjekt.

Delprosjekt 1 (sju veker) - innsamling av kunnskap: Studentane utførte, i samarbeid med bibliotekar, systematiske litteraturs $ø$ k etter modell for KBP $(5,8)$. Dei fann fire vitskaplege artiklar (9-12) og to retningslinjer $(13,14)$. Faglitteratur om ryggmargskade og ADL-trening vart nytta i tillegg. Erfaringsbasert kunnskap fekk dei ved å delta i pasientane sitt morgonstell, undervising om pasientgruppa, vegleiing og diskusjon med sjukepleiarar og ergoterapeutar som var tilsett i eininga. Gjennom samtale med pasientar og deltaking i morgonstell fekk dei innsikt i brukarane sin kunnskap om utfordringar knytt til påkleding.

Delprosjekt 1 munna ut i ein strukturert og omfattande plan som fekk namnet ADL-plan. Planen skulle nyttast som eit tverrprofesjonelt verktøy i påkledingstrening i tidleg rehabiliteringsfase. Delprosjekt 1 vart avslutta med at studentane presenterte arbeidet og drøfta resultata med prosjektleiinga og andre tilsette ved spinaleininga og ergoterapiavdelinga. Dei utarbeidde òg ein skriftleg rapport til nye studentar som deltok i delprosjekt 2.

Delprosjekt 2 (15 veker) - implementering av kunnskap: Studentane i delprosjekt 2 implementerte ADL-planen i spinaleininga. Dei deltok i morgonstell med pasientar og fekk erfaring med pasientgruppa og utfordringane deira. ADL-planen vart fylt ut i samarbeid mellom studentane og kvar pasient kort tid etter pasientane vart innlagd i eininga. Dette innebar formulering av mål for påkledingstrening, kartlegging av pasienten sine ressursar og utfordringar og skildring av framgangsmåte for å nå målet. Studentane erfarte etter kort tid at planen var omfattande og lite hensiktsmessig i bruk. På bakgrunn av desse erfaringane og under vegleiing, vart planen revidert. Ein forenkla plan, redusert frå åtte til to A4-sider, vart presentert for dei tilsette ved Spinaleininga og etter kvart òg teke vidare i bruk ved eininga.

Delprosjekt 3 (sju veker) - samanfatting og formidling av kunnskap: Studentane i delprosjekt 3 samanfatta prosjektet på bakgrunn av rapportar frå delprosjekt 1 og 2. Ein sluttrapport vart presentert for prosjektgruppa og tilsette ved Spinaleininga og Ergoterapiavdelinga. Studentane skreiv òg ein fagartikkel som vart trykt i Patetra, medlemsbladet for Landsforeningen for Ryggmargsskadde (15).

DISKUSJON. Studentane uttrykte at arbeidet med prosjektet gav dei innsikt $i$ betydinga av felles målretta og likeverdig samarbeid mellom profesjonane. Slik fekk pasienten eit betre grunnlag for å nå sine mål om tidleg meistring i påkleding. Fruktbart tverrprofesjonelt samarbeid inneber ansvar, koordinering, kommunikasjon, tryggleik på eigen rolle, autonomi, gjensidig tillit og respekt (16). Studentane opplevde ei felles forplikting til å bidra i det tverrprofesjonelle samarbeidet, og resultatet av prosjektet var knytt til

det dei klarte å skapa i fellesskap.

Vår erfaring er at praksisstudie er ein læringsarena som kan fremjar tverrprofesjonelt samar-

«Studentprosjektet skulle medverka til tettare samarbeid mellom ergoterapeutog sjukepleiarstudentar i praksisstudie.» beid gjennom fagutviklingsprosjekt. Dette samsvarar med forsking som syner at tverrprofesjonell læring skjer med godt resultat der studentar frå ulike profesjonar møtest og arbeider saman i klinisk retta praksis (17-19).

ULIKE FOKUS. Gjennom tverrprofesjonell samarbeidslæring erfarte studentane at profesjonane hadde

ulike fokus og vekta ulike aspekt ved påkledingstrening. I direkte pasientretta arbeid og i diskusjonar kring ADL-planen delte studentane fagleg kunnskap og perspektiv med kvarandre. Ved å arbeida med pasientane i påkledingstreninga, og observera kvarandre i handling, vart den andre profesjonen sin ekspertise og fokus i rehabiliteringsarbeidet tydelegare for dei.

Sjukepleiestudentane lærte mellom anna at ergoterapeutstudentane hadde eit nyansert blikk for pasientane sine ressursar og motoriske mestringsstrategiar. Dei hadde òg kunnskap om korleis praktisk tilrettelegging og pasientens kroppsstilling kunne bidra til auka sjølvstende for pasienten i påkleding. Ergoterapeutstudentane oppdaga at sjukepleiarstudentane hadde eit utvida fokus på pasientsituasjonen gjennom å ivareta pasientens integritet, hygiene, velvære og sjølvbilete under påkledinga.

Studentane erfarte at dei lærte av å samarbeide med kvarandre. Ved å dela kunnskap vart dei betre rusta i møte med pasientar og såg korleis dei kunne bidra til auka meistring for pasientane. Dette samsvarer med litteratur og forsking som seier at studentar utviklar positive haldningar til andre profesjonar og tverrprofesjonelt samarbeid gjennom felles praksisstudie $(16,19,20)$. Slik kan kvaliteten 
på arbeidet i helsesektoren auka, og pasientane få eit betre og meir heilskapleg helsetilbod (16).

PROFESJON OG ROLLE. Prosessen med litteratursøk, utarbeiding av ADL-planen og samarbeid med pasientane gav studentane høve til å verta meir merksame på fellestrekk med andre profesjonar og særtrekk ved eigen profesjon. I diskusjonar knytt til utforming av ADL-planen og målet med denne, lærte studentane å setta ord på kunnskap og klargjera for kvarandre kva dei meinte var viktig og kvifor. Slik kan profesjonsidentiteten både utfordrast og utviklast i møte mellom studentar frå ulike profesjonsutdanningar (20). Tett samarbeid og møte mellom ulike perspektiv førte til at implisitt forståing og perspektiv innanfor dei ulike profesjonane vart gjort eksplisitt. Gjennom dialog kunne studentane drøfta si eiga forståing og arbeida mot eit felles mål. Kristensen et al. (20) seier dette kan styrka fagidentiteten til studentane og auka deira medvit kring ulike profesjonar sin kompetanse og rolle i pasientbehandlinga.

ENDRA PRAKSIS. Implementering av KBP i påkledingstrening for pasientar med nyleg erverva ryggmargsskade var vektlagt i prosjektet. Prosjektet var slik ein del av fagutviklingsarbeidet ved Spinaleininga. Moyers et al. (6) seier implementering av nye metodar og endring av praksis på bakgrunn av studentrelaterte KBP-prosjekt ofte syner seg vanskeleg. Studentane sit difor igjen med lita tru på høve til å endre og betra praksis gjennom KBP som metode. Derimot er vår erfaring at ADL-planen vart implementert og bidrog til endra praksis. Den er i bruk og fungerer som eit viktig arbeidsreiskap i samarbeidet mellom sjukepleiar, ergoterapeut og pasient. ADL-planen er presentert på ein nasjonal og ein nordisk kongress, og har vakt interesse hjå tilsette ved fleire behandlings- og rehabiliteringseiningar.

STYRKE. Vi erfarte at modell for
KBP eigna seg på tvers av profesjonsutdanningane og var profesjonsnøytral. Studentane fekk erfara at ulikskap ikkje er eit hinder for felles avgjersler, men heller ein styrke. Gjennom samarbeidslæring erfarte dei at kommunikasjon, utveksling av fagleg kunnskap og synspunkt gav grunnlag for endra praksis. Dette er i tråd med Bridges et al. (16) som seier at tverrprofesjonelt praksisstudie rustar studentar til å arbeida tverrprofesjonelt etter avslutta utdanning, noko som sikrar høg kvalitet i pasientbehandlinga.

FAGLEG STØTTE. Studentprosjektet var godt forankra i leiinga og hadde brei støtte blant dei ulike profesjonane i eininga. Fleire peiker på dette som viktige faktorar

\section{«Studentane opplevde ei felles forplikting til å bidra i det tverr- profesjonelle samarbeidet.»}

for å lukkast med tverrprofesjonell samarbeidslæring i praksisstudiet $(4,16,21)$ og tverrprofesjonelt fagutviklingsarbeid etter KBP-modellen (6). Vi opplevde tett samarbeid i prosjektgruppa som viktig for å støtta studentane sitt arbeid. Prosjektleiarane bidrog til å skapa eit trygt samarbeidsklima mellom studentane, gav dei fagleg støtte og rettleiing, og var rollemodellar. Dei la òg til rette for felles møtepunkt slik at studentane arbeidde tett saman i konkrete pasientsituasjonar, i vegleiing og elles i fagutviklingsarbeidet. Studentane deltok ikkje i dei to fyrste trinna av KBP, men vart involverte i litteratursøka.

EIGARSKAP. Berg et al. (22) påpeiker at det er avgjerande at både studentar og vegleiarar har eigarskap til problemstillinga som ligg til grunn for prosjektet (22). I vårt prosjekt fekk studentane tidleg ansvar for framdrifta. Vi erfarte at grundig informasjon om bakgrunnen for prosjektet, samt å arbeida i prosjektet, gav studentane motivasjon, eigarskap og ei kjensle av kontroll. Dette til tross for at nokre av studentane tykte det var vanskeleg å ha ansvar for eit prosjekt som andre hadde initiert, ̊̊ gjennomføre eit prosjekt fordrar god struktur allereie frå starten. Utover prosjektperioden var det naudsynt å nytta prosjektplanen aktivt som eit styringsdokument for framdrift og fokus. Dei gongane vi opplevde mest utfordringar var då vi ikkje følgde dei føringane som låg der. Prosjektets varigheit over to år og prosjektleiinga sitt engasjement bidrog til at Spinaleininga fekk eigarskap til ADL-planen.

KONKLUSJON. Praksisstudiet eignar seg godt som læringsarena for tverrprofesjonelt samarbeid. Gjennom felles praksisstudie fekk studentane innsikt i kvarandre sin kompetanse, utvikla positive haldningar til tverrprofesjonelt samarbeid og styrka eigen fagidentitet. Studentprosjektet medverka til at studentar vart ein ressurs for fagutvikling i praksisfeltet. God planlegging, tett samarbeid mellom involverte partar og leiingsforankring var vesentleg. Våre erfaringar gjev grunn for å satse vidare på denne forma for tverrprofesjonell samarbeidslæring i praksisstudie. •

Takk til pasientar, studentar og tilsette som deltok i prosjektet. Takk òg til bibliotekar.

\section{REFERANSER:}

. Helse- og omsorgsdepartementet. Forskrift om habilitering og rehabilitering, individuell plan og koordinator. Oslo: Helse- og omsorgsdepartementet, 2011.

2. Straumsheim J. Forskningsgruppen Tverrprofesjonelt samabeidipraksisogutdanning HogskoniMolde V whimoldeno/ forskning/forskningsgrupper-hs/Sider/ForskningsgruppenTverrprofesjonelt-samarbeid-i-praksis-og-utdanning.aspx (04.05.2013).

Kunnskapsdepartementet. Stortingsmelding 13 Utdanning for velferd. Samspill i praksis. Oslo: Kunnskapsdepartementet, 2012

4. Kristensen D, Staib K, Norenberg D, Brekke L, Bruun L, Cas- persen S, et al. Rapporter fra Høgskolen i Buskerud Nr 91. Studenter i tverrprofesjonell klinisk praksis: Et samarbeidsprosjekt mellom Seksjon for Geriatri, Slag og Rehabilitering (GSR) ved Bærum sykehus, Vestre Viken Helseforetak, Høgskolen i Oslo og Akershus (HiOA) og Høgskolen Buskerud (HiBu). Høskolen Buskerud og Vestfold, 2012

Nortvedt M, Jamtvedt G, Graverholt B, Nordheim L, Reinar LM. Jobb kunnskapsbasert! En arbeidsbok. Oslo: Akribe
Litr. 2012

6. Moyers P, Guthrie P, Swan A, Sathe L. Interprofessional evidence-based clinical scholar program: learning to work ogether. Am J Occup Ther 2014;68:23-31.

. Hogskoleni Bergen Utviklingsmidlar til samarbeidsprosiekt melor mellom en, 2014. Tingengelig fra. htp $/ M$ tviklingsmidlar (19.06.14)

8. Nortvedt M, Jamtvedt G, Gravenholt B, Reinar LM. A arbeide og undervise kunnskapsbasert - en arbeidsbok for sykepleere. Oslo: Norsk sykepleierforbund, 2007.

9. Pillastrini P. Mugnai R, Bonfiglioli R, Curti S, Mattioli S, Maioli $\mathrm{M}$, et al. Evaluation of an occupational therapy program for patients with spinal cord injury. Spinal cord 2008:46(1):78-81.

10. Hamilton B, Deutsch A, Russell C, Fiedler R, Granger C. Relation of disability costs to function: Spinal cord injury Arch Phys Med Rehabil 1999;80(4):385-91.

11. Catz A, Itzkovich M, Agranov E, Ring H, Tamir A. SCIM - spinal cord independence measure: a new disability scale for patiints with spinal cord lesions Spina Cord 1097:35(12):850-60.

2. Burns A, Dituno J.Establishing pognosis and maxmiz

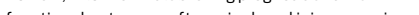
functional outcomes after spinal cord injury: a review of current and future directions in rehabilitation management. Spine 2001;26:137-45.

13. Consortim for Spinal Cord Medicine Member Organizations Outcomes following traumatic spinal cord injury: clinical practice guidelines for health-care professionals. I Spinal Cord Med 2000;23(4):289-316.

14. McKinley W. Functional Outcomes per Level of Spinal Cord Injury. Tilgjengelig fra: http://emedicine.medscape.com/ article/322604-overview (02.02.2015)

15. Espeland I, Stang M, Halleby E, Johannessen J. Mestring påkledning etter ryggmargsskade - Et tverrfaglig studentprosjekt ved spinalenheten på Haukeland universitetssykehus. Patetra 2013:30(1):8-11.

16. Bridges D, Davidson R Odegard P, Makil, Tomkowiak J.Interprofessional collaboration: three best practice models of interprofessional education. Med Educ Online [Internet]. 2011. Tilgjengelig fra: http://www.ncbi.nlm.nih.gov/pub$\mathrm{med} / 21519399$ (09.02.2015)

17. Cragg B, Hirsh M, Jelley W, Barnes P. An interprofessiona rural clinical placement pilot project. J Interprof Care 2010;24(2):207-9.

18. Jacobsen F, Fink A, Marcussen V L Larsen K. Hansen T. Interprofessional undergraduate clinical learning: results from a three year project in a Danish Interprofessional Training Unit. J Interprof Care 2009;23(1):30-40.

19. Pelling S, Kalen A, Hammar N, Wahlström O. Preparation for becoming members of health care teams: findings from 5-year evaluation of a student interprofessional training ward. J Interprof Care 2011;25(5):328-32.

20. Kristensen D, Flo J, Fagerstrøm L. Tverrproffesjonell klinisk praksis for helsefagstudenter som er en del av den ordinære praksisperioden. En casestudie fra en akutt geriatriskslag - og rehabiliteringsavdeling. Nord Tidsskr Helseforsk 2014;10(1):83-95

21. Konsmo T, Nordheim G, de Vibe M. Evaluering av 80 samhandlingsprosjekter - nøkler for å lykkes. Rapport fra Kunnskapssenteret. Notat 2013. Oslo: Nasjonalt kunnskapssenter skapssenteret. Notat 2013. Os

22. Berg M, Bruset E, Dahl M, Sveen U, Andersson L, Michelet M, Stubbings J.G. Utvikling av ferdigheter i kunnskapsbasert praksis: samarbeidprosjekt for studenter og klinikere Ergoterapeuten 2012;55(2):30-5.

FAGARTIKLER:

Fagartikler kan sendes til torhild.apall@sylkepleien.no 